\title{
¿Tendrá fuerza de realidad la tercera fuerza?
}

\author{
Aquiles Montoya
}

Resumen

\begin{abstract}
Motivado por la problemática surgida alrededor de la presunta "nueva realidad" de El Salvador, el autor discute sus alcances, después recoge el planteamiento de I. Ellacuría sobre la tercera fuerza y se pregunta, en la tercera parte, si ésta tiene fuerza de realidad. El artículo está conformado por dos vertientes, el pensamiento de Ellacuría y los datos de la realidad.
\end{abstract}

Hace algunos meses, a raíz de que se hiciera evidente la crisis del FMLN y de escuchar o leer los planteamientos de distintos representantes de los partidos que lo integraban, formulamos una serie de tesis para discutir cuáles son las características de la presunta "nueva realidad" en la cual vivimos. En la primera parte de este trabajo, exponemos algunas de estas tesis. Luego, en la segunda parte, estudiamos uno de los muchos aportes de I. Ellacuría que, entre otros, nos parece que aún tiene vigencia y puede contribuir a la búsqueda de verdaderas soluciones que sean, a la vez, soluciones verdaderas a la problemática de las mayorias populares, esto es, la "tercera fuerza". En la tercera parte nos preguntamos si tiene fuerza de realidad la tercera fuerza. Finalmente, hacemos algunas sugerencias sobre cómo estructurar la tercera fuerza.
"Pero no por huir del principismo vamos a caer en el pragmatismo". (I. Ellacuría)

1.1. Participar en elecciones bajo las reglas del sistema no implica aceptar las prácticas de los partidos tradicionales.

Un partido político que busque ser diferente y alternativo, esto es, un partido que pudiera ser de inspiración marxista ${ }^{1}$, debería también de tener una práctica política diferente, antes, durante y después de los eventos electorales. Un partido político de distinto talante no deberá de venderse como una mercancía 2 . Ciertamente, es preciso conocer las demandas objetivas y justas de las mayorías populares, pero también es preciso educarlas y crearles conciencia de que ningún partido político puede reemplazarlas o sustituirlas. El mejor partido político es aquel que acepta ser un medio para 
alcanzar los fines de las mayorías populares. Fines que no tienen por qué identificarse, necesariamente, con la consecución de una forma predeterminada y conocida de organización social diferente a la capitalista, ya que ser marxista no tiene por qué implicar necesariamente trabajar por construir el denominado socialismo real3, como la única forma de organización social altemativa a la capitalista. Sobre el particular, Antonio González plantea "todo parece indicar que el socialismo real de tipo soviético ha desaparecido como alternativa real, y cuanto antes se tome conciencia teórica y práctica de este hecho, y se saquen todas las consecuencias, más rápidamente se podrán comenzar a articular caminos concretos de liberación"4.

A nuestro entender, los rasgos de la nueva sociedad ya los están construyendo desde su base las mayorías populares. Esa nueva sociedad se caracteriza, primariamente, por ser una opción por la vida, fundamentada en la solidaridad y en el vivir comunitario. Una sociedad en la cual el trabajo, lejos de ser una actividad alienada y alienante, se transforma en una actividad potenciadora del desamollo humano. Esta parece ser la mejor opción para los países pobres. Y tenemos la gran ventaja de poder ser creativos y dejar ya de importarlo todo, hasta nuestra forma de vida.

Por otra parte, el hegemonismo y el vanguardismo deberían de ser excluidos definitivamente de un partido que aspire a ser una caja de resonancia de las aspiraciones de los sectores populares, lo cual pasa, necesariamente, por practicar la democracia en el interior de dicho partido. Tanto los candidatos como las propuestas deberían ser el resultado de un esfuerzo concertado entre los movimientos sociales afines y los militantes del partido. Esto exige a su vez el reconocimiento de la autonomía del movimiento social y una política de alianzas ante las coyunturas trascendentales, sean éstas electorales o no.

\subsection{La actividad política en el interior del siste- ma no implica necesariamente estar a su fa- vor.}

Si tenemos presente la realidad propia del sistema, el cual está fundamentado en la explotación del trabajo asalariado, cuya lógica es la búsqueda incesante de la ganancia, así como sus tendencias inherentes - la acumulación sin límites de capital y la concentración y la centralización de la riqueza así como también la forma de vida que todo ello implica, fundamentada en el consumismo, depredadora del ecosistema-, resulta obvia la actitud antisistema de todos aquellos que por diferentes vias hemos llegados a conclusiones similares. No olvidemos tampoco que esa forma de vida capitalista no es universalizables, sencillamente, porque los recursos del planeta no alcanzan para todos. La actitud antisistema, en ningún momento, puede ser incompatible con una actividad política tendiente a propiciar mejores condiciones de vida para las mayorías empobrecidas.

Es claro que no se puede eliminar la explotación de la clase trabajadora preservando el sistema capitalista, pero es posible conseguir que no sea sobre-explotada. No es posible cambiar la lógica del sistema, pero es posible promover el desarrollo de otras lógicas diferentes a la capitalista. Así como es posible también demandar mejores condiciones de vida en general o de vivienda, de salud, de educación, de empleo, etc., para la mayoría de la población. Y ello es tan lícito, aunque no se comparta la visión capitalista, como la burguesía considera lícito su quehacer político, aun a sabiendas de que su objetivo es preservar sus privilegios de clase y en ningún momento generar un desarrollo económico y social que alcance a los pobres y marginados6.

1.3. El movimiento social debe realizar su propia actividad política, la cual no tiene por qué ser anti-partidaria.

Para que exista un movimiento social fuerte y con capacidad para incidir en el quehacer nacional, lo primero que se requiere es una organización en los distintos niveles posibles. Pero ello, a su vez, no implica adoptar una actitud antipartidaria, o peor aún, buscar reemplazar a los partidos políticos. Lo primero le conduciría a una ineficacia en su actividad colectiva y lo segundo, lo desnaturalizaría. De allí que su práctica deberá estar guiada por la autonomía, la concertación y las alianzas.

Autonomía en la definición de su línea de activi- 
dad gremial, reivindicativa o política. Concertación como mecanismo inicial para enfrentar la propia problemática y la búsqueda de soluciones. Sin embargo, la concertación no debe de entenderse como claudicar, ya que, sin ser inflexibles en las demandas, es preciso tener claro que la intransigencia de la contraparte debe ser combatida con acciones legales o de hecho, teniendo sumo cuidado en respetar la progresividad de los distintos niveles y en dejar claro ante la opinión pública el proceso seguido. Y ello, obviamente, no puede ser considerado, desde ningún punto de vista racional, como acciones desestabilizadoras, ya que si las demandas justas y racionales se resolvieran pronta y adecuadamente, no habría por qué llegar hasta las acciones de hecho. Las alianzas deben buscarse en los distintos niveles y con distintas organizaciones integrantes de las fuerzas sociales, así como con los partidos o con el partido al cual se sienten más próximas o con el cual haya mayor coindicencia en los principios e intereses?.

\section{La tercera fuerza}

La realidad nos está indicando que existe una crisis tal, en los distintos ámbitos del quehacer social —en sentido amplio-, que se nos impone como un imperativo categórico - para decirlo kantianamente- o que existen condiciones objetivas dicho marxistamente- que nos hacen presente la necesidad de buscar propuestas altemativas que posibiliten a las mayorías populares de nuestro país, salir de su condición de miseria económica y de su marginación política, social y cultural. Esto adquiere mayor fuerza de realidad y de razón, al conocer - aunque sólo sea marginalmente- el grado de descomposición que presentan los distintos partidos del FMLN, asi como los niveles de corrupción e impunidad en que han caído algunos de sus dirigentes, lo cual parece ser un secreto a voces que cada vez se va generalizando más. Ya no digamos la recua de partidos políticos tradicionales que no pasan de ser, generalmente, refugio de desocupados.

Por otra parte, nos esperan cinco años más de un gobierno que no responde a los intereses de las mayorías populares con una oposición política que hasta el momento no logra hacer oposición real,

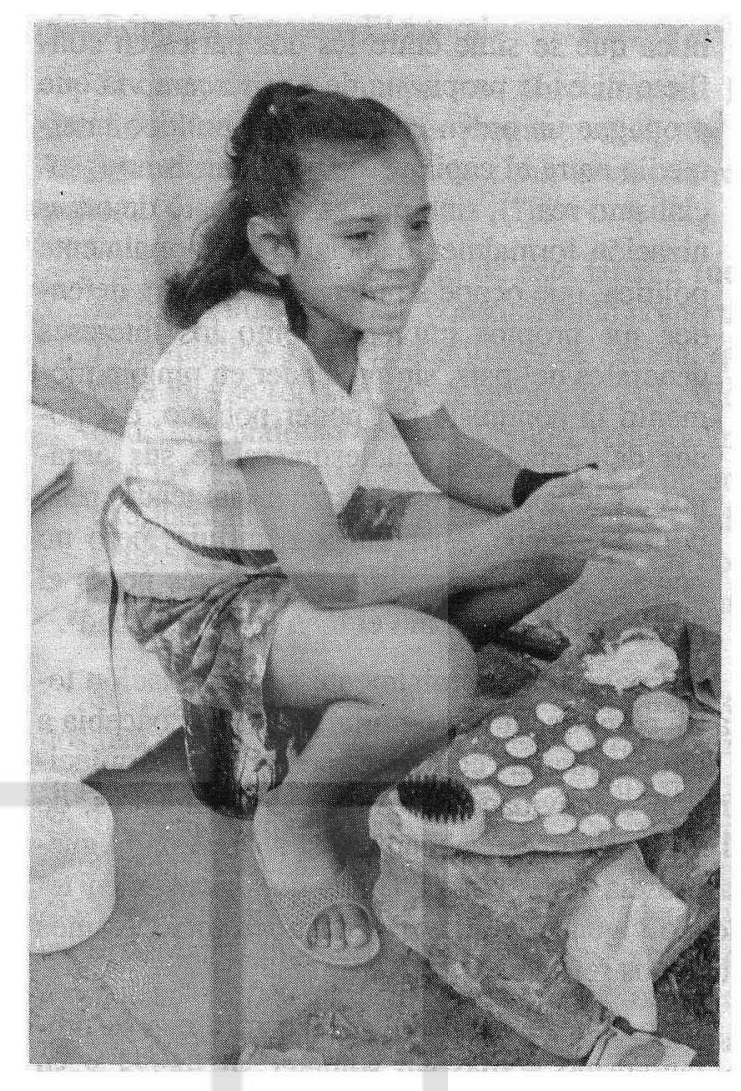

por estar más ocupada en sus luchas intestinas, algunas más publicitadas que otras, pero no por ello menos reales, lo cual no deja de ser muy decepcionante, ya que pareciera que los políticos se preocupan primariamente por sus intereses personales y por eso se ocupan primero de garantizarse el control de sus partidos, olvidando cuál es la razón de ser de la política y del político.

\subsection{La tercera fuerza: una visión ellacuriana}

Por todo ello, nos parece que aquella formulación de nuestro rector mártir, el doctor Ignacio Ellacuria, acerca de la tercera fuerza, pudiera ser parte de la respuesta a la crisis del país. Ya que su propuesta adquiere hoy quizá más actualidad que ayer $\mathrm{y}$, además, las condiciones son más propicias para que no sea desnaturalizada e instrumentalizada tal como lo fue en el pasado. Pero ¿cómo era concebida esa tercera fuerza por Ellacuría?

La "tercera fuerza" no es una nueva fuerza po- 
lítica que se sitúe entre las dos partes en conflicto ni es la propuesta de una tercera vía que propugne un orden económico y político intermedio entre el capitalismo y el marxismo (¿socialismo real?), sino que es un intento de organización formalmente social y no formalmente política, que ocupe su fuerza social para defender sus propios intereses como los intereses generales del país, sin pretender en ningún momento la conquista del poder político, del poder del Estado en cualesquiera de sus órganos... Ciertamente, esta fuerza social tendrá peso político, puede tener un gran influjo, pero no por eso es política, porque su interés no es el poder del Estado, sino el bien de la sociedad8.

Sin negar que parcialmente su formulación tenía un componente coyuntural, en tanto concebía a la "tercera fuerza" como una posibilidad para incidir con efectividad sobre los acontecimientos, de tal manera que éstos condujeran al final de la guerra, poseía otros componentes que aún siguen teniendo vigencia y que es preciso retomar. Veamos a que nos referimos.

La propuesta es que el pueblo recupere su protagonismo activo sin someter su fuerza y su posible organización... mirando por sí y sus intereses, sin delegarlos, al menos en un primer momento, en ninguno de los poderes que se disputan el mando del Estado. La hipótesis que aquí se avanza es que si esta tercera fuerza social se dinamiza puede conducir no sólo a la solución del conflicto, sino también a delinear los puntos fundamentales de un proyecto social al cual los políticos debieran someterse?.

En primer lugar, Ellacuría habla de que el pueblo -o las mayorías populares como posteriormente lo precisará- recupere su protagonismo, mirando por si y por sus intereses. ¿Acaso tal aseveración no es precisamente lo que ahora se requiere ante la crisis general que abate a las mayorías populares? Sobre todo ante la crisis de confiabilidad que experimentan los partidos políticos en general y el FMLN en particular. ¿Qué se puede esperar de ARENA? ¿Qué del FMLN? ¿Qué de la democracia cristiana? Ciertamente, las mayorias populares poco menos que nada. En segundo lugar, si la hipótesis que formulara Ellacuria se hubiese cumplido, el proyecto social resultante de los acuerdos de paz, no sólo hubiese sido diferente —mucho más beneficioso para los sectores populares-, sino que, a su vez, hubiese existido capacidad para exigir su cumplimiento, porque el proyecto hubiera sido un proyecto de las mayorías populares 10 . Pero bien, lo importante no es lo que pudo haber sido, sino lo que aún puede ser y "el delinear los puntos fundamentales de un proyecto social" sigue siendo una tarea pendiente. El padre Ellacuria planteaba además,

se trata de que esa tercera fuerza social haga valer su poder social de modo que incida sobre el poder político, de modo que ella determine en última instancia, a éste y no sea éste el que la determine a ella, en última instancia. Lo político y lo social son dos esferas de poder que, en su especificidad, tienen mutuas relaciones y determinaciones. En El Salvador la predominancia la tiene, en un grado excesivo, lo político (incluido todo el aparato estatal, militar, de los partidos políticos y de las relaciones internacionales, etc.). Con lo cual no es el pueblo, como fuerza social, el sujeto real de su propio destino político, sino que lo son sus presuntos representantes, quienes miran más por los intereses propios, derivados de estar o no estar en el poder, que por los intereses reales de la población'11.

En la actualidad ya existe, al menos de manera declarativa, la intencionalidad de algunos dirigentes del FMLN de no instrumentalizar a las organizaciones gremiales, pero más importante es el hecho de que algunas organizaciones y asociaciones de trabajadores de los distintos ámbitos de la actividad económica y social no están dispuestas a dejarse instrumentalizar. Adicionalmente, para más

\section{La actividad política en el interior del sistema no implica necesariamente estar a su favor.}


de algún dirigente del Frente existe la preocupación manifiesta de los inconvenientes que presenta para el desarrollo del movimiento social el estar "dando línea"; sin embargo, no dejan de inquietarse ante la posibilidad de que ese movimiento social "no alineado", adopte una postura apolítica o peor aún, anti-partidaria.

En el planteamiento de Ellacuría es claro que la determinación en última instancia del poder político debe provenir del poder social. Resulta obvio que esto asuste y sea motivo de alarma para las dirigencias verticalistas, quienes al tomar decisiones políticas ni siquiera toman en cuenta a sus bases partidarias, ya no digamos a las fuerzas sociales. Esta aseveración fue un hecho manifiesto durante las pasadas elecciones al momento de formular las plataformas programáticas. Estas fueron más el resultado de las elucubraciones de intelectuales de escritorio que de una consulta a las fuerzas sociales o mejor aún, dichas plataformas no responden a las exigencias de las distintas fuerzas sociales. Esto se aplica tanto a la Coalición como a los partidos Demócrata Cristiano, de Conciliación Nacional y ARENA, partido que como es harto conocido responde a los intereses de una fracción de la clase capitalista, la cual, con seguridad, incidió en la plataforma programática de dicho partido, pero $i y$ el resto de las fuerzas sociales, aquellas que conforman la mayoría de la población? Estas siguen marginadas de la vida social y política en nuestro país.

Por otra parte, el P. Ellacuría formula dos puntos de suma trascendencia, el del sujeto histórico y el de los intereses del político. Ambos temas siguen teniendo vigencia hoy, como la tuvieron en el pasado. Las presuntas vanguardias han usurpado al pueblo su carácter de subjetualidad y el curso de la historia ha venido siendo determinado, demasiado a menudo, más por los intereses personales de las dirigencias de las presuntas vanguardias de una u otra clase social, que por los intereses de las fuerzas sociales populares. Esto fue evidente con motivo de la firma y las exigencias de cumplimiento de los acuerdos de paz, como lo ha sido también en la conformación de la directiva de la nueva asamblea legislativa o en la elección de los magistrados de la Corte Suprema de Justicia y del Tribunal Supremo Electoral.

Si compartimos, aunque sea parcialmente, las formulaciones anteriores, la pregunta obligada es la siguiente: ¿qué hacer? A lo cual, Ellacuría responde:

La estrategia fundamental de esta tercera fuerza social implicaría, su consolidación como tal. Esto implica a su vez dos líneas de acción: que cada una se robustezca en su propia especificidad, buscando al mismo tiempo relacionarse con las demás hasta formar una especie de unidad nacional, y que mantengan una clara independencia respecto de las dos fuerzas en conflicto, de modo que no caigan en forma alguna de subordinación 12 .

Se podria argüir que ahora ya no existen esas dos fuerzas en conflicto, a las cuales la tercera fuerza pudiera quedar subordinada. Pero siguen existiendo fundamentalmente dos fuerzas: la izquierda (diezmada) y la derecha (fortalecida). $\mathrm{Y}$ ambas fuerzas existirán con mayor o menor preponderancia, mientras exista el conflicto de intereses propio de cualquier sociedad clasista y con mayor razón en países como los nuestros, donde las diferencias socio-económicas se dan de manera tan magnificada. Con todo, lo fundamental de la estrategia es que la tercera fuerza se consolide, lo cual pasa por la organización de sus distintos integrantes en sus distintos niveles hasta conformar una organización social nacional grande y fuerte $y$, por otra parte, por una organización que conserve su independencia de las estructuras partidarias sean del signo que fueran.

A estas alturas, surge la pregunta acerca de ¿cuáles serían los elementos aglutinantes de la tercera fuerza? o ¿cuál sería el tegumento que posibilitaría su conformación? A lo cual Ellacuría responde - prescindiendo de los elementos coyunturales-en los siguientes términos:

Esta tercera fuerza social puede coincidir en unos cuantos puntos, muchos de los cuales ya los ha expresado a través de algunos de sus obvios componentes: (a) la causa fundamental del conflicto salvadoreño es la injusticia estructural y sólo con su superación se logrará su solución definitiva.. (d) en lo económico debe buscarse 
una solución a fondo que, mediante las reformas estructurales, rompa el esquema de explotación y opresión con la consiguiente superación de una lucha de clases violenta; esto no implica la anulación de la empresa privada, sino tan sólo poner coto a sus abusos tradicionales; (e) en lo político se buscan formas efectivas para satisfacer los intereses y las demandas de las mayorías populares, de modo que se garantice la apertura democrática y el máximo respeto posible de los derechos humanos, sin descuidar la posibilidad del pluralismo político; (f) en lo social se pretende dar toda prioridad a las exigencias responsables de todas y cada una de las distintas organizaciones sociales que la sociedad se da a sí misma en razón de las necesidades y de las condiciones objetivas...13.

Como es evidente, los literales anteriomente citados conlienen tareas que aún no se han iniciado o, en el mejor de los casos, que todavía no se han completado. Es obvio y por ello tuvo que ser reconocido incluso por el ex presidente Cristiani que la causa fundamental del pasado conflicto se encuentra en la injusticia estructural. Asimismo, debiera también ser obvio que su solución definitiva pasa por la superación de esa injusticia estructural. Sin embargo, seguimos padeciendo esta calamidad sin que se haga nada al respecto, lo cual reafirma la necesidad de impulsar la tercera fuerza como una alternativa distinta a las conocidas hasta ahora.

En el ámbito económico, Ellacuría observaba con bastante lucidez la necesidad de reformas estructurales y aunque en otros trabajos manifestó una posición anti-capitalista14, para la tercera fuerza reservaba la superación de la lucha de clases violenta dentro del sistema. Obviamente, esto no es poca cosa y, dadas las condiciones objetivas actuales, se tendría que ser muy iluso para no percatarse de ellas. Sin embargo, ello no tiene por qué conducimos a renunciar a la utopia. En consecuencia, su tesis de la necesidad de reformas estructurales sigue teniendo sentido hoy, quizás más que ayer, cuando se pensaba que por medio de los acuerdos de paz, era posible lograr tales reformas que sin abolir el sistema lo hicieran estructuralmente menos injusto. $O$ cuando se creía que a partir de la toma del poder del Estado se iba a proce- der a realizar tales reformas.

El tercero de los literales formulados por Ellacuría parece ser el que mayores avances presenta, en términos de concreción, al menos en lo referente a la apertura democrática y al pluralismo político, aunque siga estando pendiente el respeto de los derechos humanos, los cuales, obviamente, no se reducen sólo a los derechos políticos, sino que también comprenden los derechos económicos y sociales, así como el respeto a la vida, sin lo cual no tiene ningún sentido hablar de derechos humanos.

Finalmente, establece la prioridad que tienen las exigencias de las fuerzas sociales organizadas en razón de sus necesidades y de las condiciones objetivas, con lo cual muestra no sólo la madurez de su pensamiento, sino que también revela la responsabilidad con que asumía su trabajo como rector de una universidad que se definió a sí misma como "la universidad para el cambio social". En consecuencia, siempre fue un crítico de las demandas de las fuerzas sociales que respondieran, única y exclusivamente, a fines políticos, pero no por eso dejó de apoyar desde su propio quehacer académico, la lucha por la satisfacción de las necesidades de las mayorías populares, aunque cuidando de respetar el ámbito de lo posible. Así, por ejemplo, fue un entusiasta promotor de la necesidad de efectuar un proceso de reforma agraria, aun cuando se trataba del primer esfuerzo fallido de transformación agraria iniciado por el presidente Arturo A. Molina. Pero más que recordar lo hecho, nos interesa mostrar la vigencia que sigue teniendo su pensamiento y en tal sentido cabria añadir lo siguiente:

...a esta tercera fuerza compete buscar seriamente soluciones económicas que ataquen de raíz el "principio" de nuestros males. Bien puede asegurarse que el "principio" de nuestro problema es fundamentalmente económico y no, por ejemplo, la maldad de los corazones. Mientras no se resuelva el problema económico o entre en camino de resolverse, el conflicto social seguirá vigente. La injusticia estructural no sólo tiene la característica de implicar una mala distribución en el esfuerzo y en la redistribución, sino también la de una escasa pro- 
ducción cuantitativa y cualitativa; es, por lo tanto, además de un problema ético y político, un problema técnico de gran envergadura, al cual en El Salvador se ha dedicado muy poco pensamientols.

Este planteamiento nos remite al estudio de la problemática económico-social aún predominante en el país, porque la injusticia estructural, así como sus implicaciones, sigue siendo una realidad cotidiana. Pero antes de proceder a examinar la problemática actual de las mayorías populares, las más afectadas por la injusticia estructural, es necesario explicitar quiénes eran a juicio de Ellacuría los integrantes de la tercera fuerza:

Sin ánimo de ser exhaustivos pueden señalarse, ante todo, los sindicatos y sus equivalentes, tanto en la ciudad como en el campo, que saben perfectamente cuáles son sus intereses y que, unificados, pueden tener una fuerza muy grande... También la Iglesia debe situarse en este plano, pues en nuestro contexto tiene, por varias razones históricas hoy todavía vigentes, una fuerza indiscutible... El sector educativo y junto a él con cierta autonomia el sector intelectual y especialmente el sector universitario - profesores y alumnos- representan por su número, su preparación y su capacidad concientizadora y movilizadora una fuerza social específica... El sector profesional es otra típica fuerza social, capacitada para contribuir con su presión social a defender sus intereses sin perder de vista un marco general favorable a los intereses nacionales... El sector de la pequeña y mediana empresa, fundamental para el desarrollo del país, no acaba de consolidarse frente a la prepotencia de la gran empresa, pero por su propia naturaleza y por su propia supervivencia, tendría que mostrarse más activo e interesado en los grandes problemas nacionales.

Asimismo, el sector popular no organizado políticamente tiene distintas posibilidades para hacerse sentir en el ordenamiento del proceso nacional16.

En un trabajo posterior retoma esta temática y quizá con mayor claridad expone:

Ante todo, está la fuerza laboral, aunque a ve- ces subordinada a fuerzas políticas y aun a intereses extranjeros. Normalmente, se aglutina en forma de sindicatos, cooperativas, uniones, confederaciones, etc...

En segundo lugar, están aquellos sectores de la población que constituyen, en sí mismos, la parte más numerosa de las mayorias populares... Entre ellos puede nombrarse el gran ejército de los sin trabajo regular, de los desempleados... está el gran número de los desplazados... está el grupo de los marginados y los pobladores de tugurios... Todos ellos no son gentes disgregadas. Tienen problemas e intereses comunes y, en parte al menos, no son ajenos a organizarse.

Queda otro conjunto de fuerzas que por distintas razones contribuye de manera importante al trabajo social y que podría ser un factor dinámico no sólo del desarrollo social... Está, en primer lugar, el conjunto de iglesias, sobre todo la católica... Está también el sector uni-

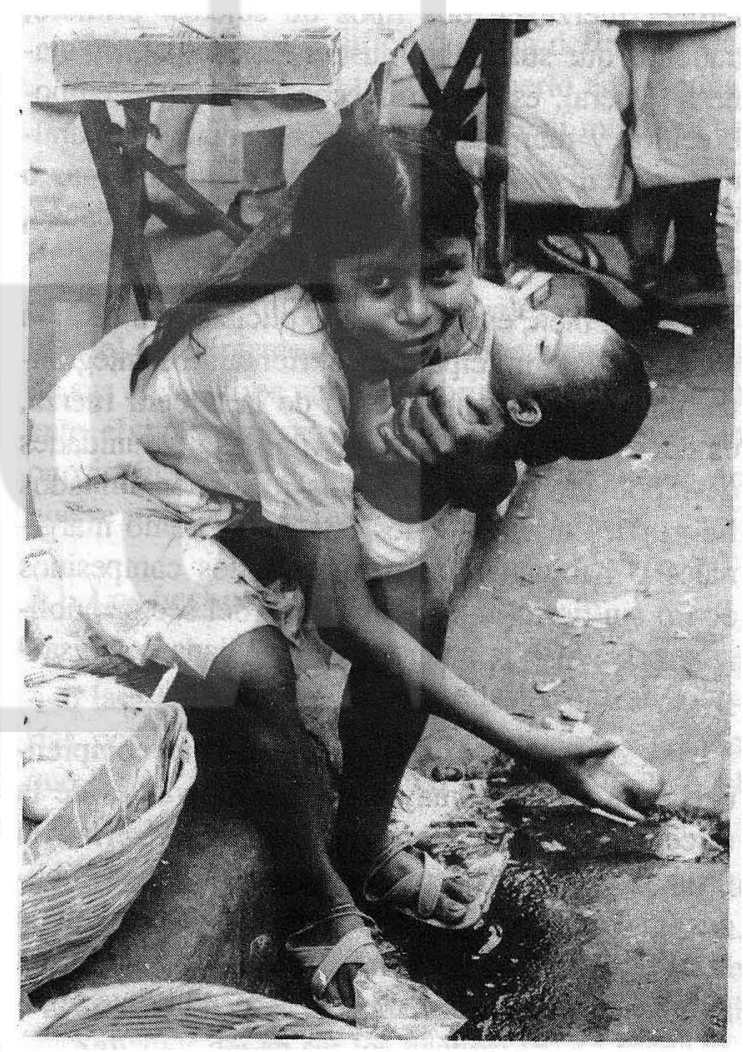


versitario y, más ampliamente, el sector educativo... Está asimismo el sector de la iniciativa privada, no aglutinado en la Asociación Nacional de la Empresa Privada (ANEP) y en las gremiales afines... Está, finalmente, el conjunto de sectores profesionales, el cual, por su número y su formación, podría constituir uno de los pilares fundamentales del progreso social17.

En esta segunda cita sobre los integrantes de la tercera fuerza existe una mayor precisión, si acaso, habría que añadirle tan sólo unos cuantos conjuntos, como las comunidades organizadas de repobladores y repatriados, incluyendo a los desmovilizados, las organizaciones de mujeres y las organizaciones no gubernamentales vinculadas con los sectores populares, sean urbanos o rurales. Si bien estas últimas por lo general tienen una vinculación políticas partidaria, por su propia naturaleza, tienden a desvincularse de los institutos políticos bajo cuya sombra nacieron para obtener una mayor credibilidad.

Por otra parte, tal vez no resulte demasiado atrevido pretender agrupar a los integrantes de la tercera fuerza en dos tipos de sujetos: primero, aquellos que sufren la injusticia estructural de manera general, esto es, los económicamente empobrecidos y marginados política, social y culturalmente y en segundo lugar, los que estando más o menos exentos de sus consecuencias acompañan, apoyan, se solidarizan con los primeros.

Ahora bien, es necesario explicitar cuál sería la problemática principal que enfrentan los integrantes del primer agrupamiento de la tercera fuerza, es decir, el sector cooperativo18, las comunidades de repobladores y repatriados 19 , los denominados informales urbanos 20 , los conocidos como marginales o habitantes de tugurios 21 , los campesinos con o sin tierra22, los asalariados del sector público y privado23, la pequeña y la mediana empresa 24 y los desmovilizados de uno y otro bando 25 .

Por otra parte, existen problemas que comprenden a un espectro mayor de los integrantes de la tercera fuerza ya mencionados. Estos serían la privatización de las empresas e instituciones públicas (dado que se trata de activos propiedad de toda la sociedad y no de un determinado gobierno en particular), los tratados de libre comercio (que segu- ramente conducirán al cierre de empresas, con el consiguiente incremento del desempleo), la orientación y las consecuencias de la implementación del modelo económico neoliberal (el cual ya demostró su fracaso en términos sociales en países que se consideran como. un ejemplo a seguir); el cambio en la orientación de la política social (la cual generará, en el mediano plazo, una mayor marginación social, en términos de vivienda, salud y educación), la problemática ecológica que nos remite a un modelo de desarrollo sostenible (el cual, sencillamente, es incompatible con el modelo neoliberal), la problemática de género (que por fin está adquiriendo estatuto de problema social, sin olvidar que está traspasada por los intereses de clase), etc.

Cabria preguntarse, entonces, ¿cuál sería el objetivo último de la conformación de la tercera fuerza? A ello, Ellacuría responde en los siguientes términos:

El objetivo es claro y puede formularse en la siguiente pregunta: ¿qué es lo más conveniente para el desarrollo económico del país, entendido éste como un medio para que las mayorias populares alcancen cuanto antes la satisfacción de sus necesidades fundamentales y la posibilidad de un desarrollo verdaderamente humano? El modelo económico tiene un componente político sobre el cual no es fácil alcanzar un consenso entre quienes piensan desde las minorías y quienes piensan efectivamente desde las mayorias, pero tiene exigencias objetivas sobre las cuales es más fácil la coincidencia26.

Aunque cuando Ellacuría escribió el trabajo anterior aún no se veía con claridad la novedad de la estrategia de desarrollo alternativo que iba surgiendo desde los sectores populares, somos de la opinión que se hubiera entusiasmado con ella, tal como lo hizo con los planteamientos del padre Segundo Montes, a propósito de las experiencias de los refugiados en Honduras. $Y$ es que esa estrategia altemativa a la que hemos denominado nueva economía popular cumple con los requisitos planteados por el padre Ellacuria, es decir, que las mayorías populares logren la satisfacción de sus necesidades fundamentales y constituya, a su vez, un desarrollo verdaderamente humano. Ciertamente, 


\section{La determinación en última instancia del poder político debe provenir del poder social.}

la estrategia popular es mucho más restrictiva en cuanto a sus sujetos que los integrantes de la tercera fuerza y en ese sentido, los integrantes de la nueva economía popular constituirían tan sólo un segmento de aquélla, junto a otras fuerzas sociales. Pero por otra parte, la posibilidad de conformar un solo bloque no se descarta y es claramente posible aunque, para comprenderlo de mejor manera, sea necesario referirse a los criterios de inclusión-exclusión en la tercera fuerza. Ellacuria, lo formulaba en los siguientes términos:

La misión principal de esta tercera fuerza sería, a mediano plazo, potenciar un desarrollo integral y justo que tuviera en cuenta como meta principal la superación del estado de injusticia estructural, causa principal de casi todos nuestros males.

El señalamiento de la superación de la injusticia estructural como objetivo fundamental tiene como propósito primario definir el carácter y la orientación de esta tercera fuerza. Quienes no participan de este propósito, porque no reconocen esa injusticia estructural o no reconocen las causas de la misma, no entrarian a formar parte de la tercera fuerza27.

Así, pues, la tercera fuerza cubre un amplio espectro de la sociedad civil, pero sin reducirse a ella en cuanto quedan excluidos de la misma no sólo lo generantes de la injusticia estructural, lo cual parece una obviedad, sino también quienes no la reconocen o no reconocen las causas de la misma. Nos parece que el punto es de suma trascendencia en la actualidad, ya que muchos integrantes de las mayorías populares hablan de los esfuerzos de la sociedad civil, de la organización de la sociedad civil, etc., sin haber entendido a cabalidad qué cosa es la sociedad civil y en realidad, sus planteamientos se corresponden más con la conceptualización de la tercera fuerza de Ellacuría que con la sociedad civil gramsciana.

\section{3. ¿Tendrá fuerza de realidad la tercera fuerza?}

Quisiéramos iniciar esta parte con algunas con- sideraciones acerca del epígrafe con que iniciamos este trabajo, pero para ello debemos citar el texto completo del cual fue extraído:

Pero no por huir del principismo vamos a caer en el pragmatismo. El principismo parte de la idea de que sólo los hechos conformes a los principios son hechos aceptables, mientras que el pragmatismo parte de la idea de que la posibilidad no tiene nada que ver con la normatividad y de que algo es siempre mejor que nada. El principismo tiende a ser intransigente, aunque suele ser más coherente y disciplinado. El pragmatismo tiende a ser acomodaticio y errático. Aquél tiende a ser más idealista, en el sentido peyorativo del término, mientras que éste tiende a ser utilitarista, también en un sentido peyorativo. Frente a ellos hay que buscar dialécticamente una posición superior que es la del realismo, por difícil que sea definir el realismo y más difícil todavía ponerlo en práctica. Es la mera realidad... que no es ni mero hecho ni mero principio la que debe determinar, en última instancia, tanto los principios como las conductas 28 .

Tal parece que en las actuales condiciones, ante el principismo de los neoliberales y algunos de sus adversarios no menos principistas, así como ante el pragmatismo de algunos dirigentes de la oposición, sea ésta más o menos de izquierda, lo que se impone es el realismo.

\subsection{Los hechos y su realidad}

Siguiendo siempre a Ellacuría, la problemática - o las problemáticas- que aquejan a las mayorías populares exigen de una verdadera solución que llegue a ser una solución verdadera29, lo cual a su juicio exige:

la conjunción de la verdadera solución con la solución verdadera debe hacerse partiendo ... de la realidad de los hechos... (a) el punto de partida de una búsqueda de solución para $\mathrm{El}$ Salvador deben ser los hechos; (b) no todos los 
hechos tienen la misma significación ni validez o jerarquía, sino que hay hechos más o menos reales; '(c) sólo detectando la realidad de los hechos puede avanzarse hacia algo que sea a la vez solución verdadera y verdadera solución ${ }^{30}$.

La realidad de los hechos puede ser también entendida, a juicio de Ellacuria, como "hechos fundamentales" y será precisamente esa realidad de los hechos la que permita responder a la interrogante que constituye el título de este trabajo: ¿Tendrá fuerza de realidad la tercera fuerza?

Veamos de qué hechos fundamentales hablamos y qué fuerza de realidad poseen éstos. Los hechos pueden clasificarse en dos categorias, los exigentes o exigenciales y los posibilitantes para el surgimiento de la tercera fuerza. Por hechos exigentes habría que entender aquellos que, siendo reales, tienen tal fuerza de exigencia que pueden conducir al surgimiento de una nueva realidad, bajo determinadas condiciones. Y por hechos posibilitantes entendemos aquellos que, siendo reales, estarían posibilitando que los hechos exigentes condujeran al surgimiento de una nueva realidad. Así, por ejemplo, el hambre se presenta como un hecho exigente y el comer como un hecho posibilitante de que el hambre dé lugar a una nueva realidad: la saciedad. Otro ejemplo, la necesidad de afecto se presenta como un hecho exigente, mientras que la correspondencia afectiva se presenta como un hecho posibilitante de que la necesidad de afecto dé lugar a una nueva realidad: el amor correspondido.

La primera pregunta a la cual debemos de dar respuesta es, ¿serán realmente hechos, tanto los exigentes como los posibilitantes, propuestos por nosotros? Y adicionalmente, ¿serán hechos fundamentales? De ello es que vamos a ocuparnos en las siguientes páginas.

\subsection{Los hechos exigentes}

\subsubsection{La crisis de y en los partidos políticos, principalmente, los de oposición y el FMLN, en particular}

El hecho tiende a caracterizarse por su obviedad, al punto que no se discute su realidad; sin embargo, lo que puede discutirse es la intelección del mismo, así como sus causas generantes. Digamos provisoriamente que la crisis de los partidos políticos es un hecho evidente. No obstante ello, es posible encontrar opiniones muy diversas respecto a como se entienden la crisis y sus causas. Así tenemos, por ejemplo, lo que nos manifiestan distintos intelectuales 31 .

Joaquín Arriola intelige las crisis de los partidos políticos como:

Ausencia de liderazgo, de dirección. Ausencia de dirección legitimada por las bases y ausencia de dirección en el sentido de liderazgo, incapacidad para transmitir propuestas a la sociedad o de captar propuestas de la sociedad.

Las causas generantes de la crisis para Arriola serían las siguientes:

(a) ausencia de renovación generacional, que sólo ARENA la tiene; (b) falta de capacidad de autofinanciación, conducente a cierta dependencia, ya sea del capital, en el caso de ARENA, o a la dependencia externa, en el caso de la social democracia o la democracia cristiana; (c) ausencia de proyectos claros que respondan a la falta de lectura clara de la realidad nacional; (d) la propia crisis del Estado. Cuando el marco institucional en el cual se mueven los partidos y las políticas públicas diseñadas desde el Estado tienen un margen de maniobra cada vez más estrecho, por un lado, por la creciente globalización, y por el otro, por la enorme dependencia de los fondos extemos en las políticas públicas, se dificulta el diseño de estrategias partidarias y contribuye a agravar la crisis de los partidos. El ámbito institucional y la capacidad de transformación desde ese ámbito institucional es cada vez más estrecho.

Por su parte, Guidos Vejar explica que

La fenomenología de la crisis es algo que me ha venido interesando desde hace algún tiempo, porque a veces es muy importante saber $l a$ qué causas se le debe atribuir una alteración y decir si eso es crisis y qué tipo de crisis es o qué tipo de alteración es? Yo creo que la crisis por la que está atravesando la izquierda de El 
Salvador es una crisis que se debe a su propio éxito.

Después de un breve recorrido histórico, añade lo siguiente:

La fenomenología de la crisis se manifiesta fundamentalmente, quizá, cuando el Frente debe de asumir un pensamiento y una acción desde lo estatal. Cuando se integra al Estado, creo yo, que alli es donde viene el problema. En la medida que logra ser parte del Estado aparecen las diferencias, unos comienzan a opinar que debe haber una estrategia de tipo estatal, que les permita orientarse y

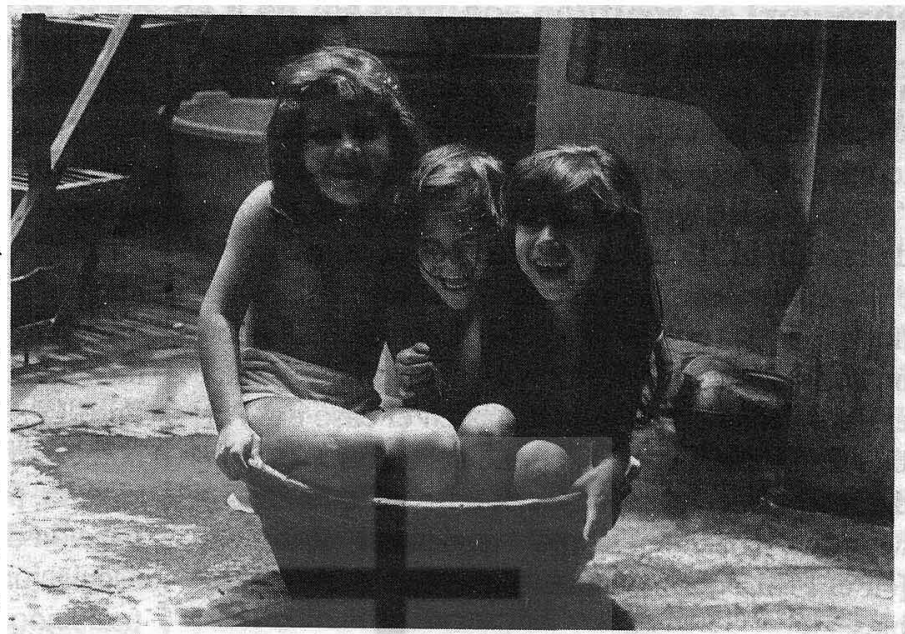
dirigirse a un nuevo pacto político para hacer las reformas de tipo económico-social. Tener una voluntad de tipo estatal. No creo que el problema en el Frente sea de ideología, al menos, no del marxismo-leninismo, que ya antes había sido abandonado por algunos partidos del Frente sin que se generara una crisis. El elemento extraño, que lleva a la crisis, es el Estado, que lleva a una diferenciación de la izquierda, a volverse realmente opciones, respecto al Estado, a las distintas posiciones que cada uno tiene.

En cambio, Ricardo Bracamonte manifestaba que uno de los problemas del FMLN radica

en el modelo a seguir, parece que es uno de los más importantes. Por un lado está el modelo socialista y por otro, el modelo que está planteando Joaquín Villalobos y la Resistencia Nacional con la social democracia. Pero no es sólo eso, la crisis, esto sería una crisis teórica, hay una crisis práctica, producto de la relación en que se han movido los cinco partidos del Frente y es la crisis de liderazgo -que nadie quiere dejar de ser líder y que están acostumbrados... a que cada quien manda su propio grupo-. Por otra parte, los "acuerdos" los han manejado sólo para soluciones coyunturales. Existe una ambición de poder, ya que nadie quiere dejar el "tamal", ni quedar de segundo.

Dado que este aspecto es clave, buscamos otras opiniones. Entre ellas, la de Monseñor

Rivera, quien calificó la crisis de los partidos políticos como un "terremoto que merece reflexión".

Se podría pensar que se trata de algo intrascendente, de un reacomodo a la nueva realidad después de los acuerdos de Chapultepec; sin embargo, una mirada más atenta descubre un hecho preocupante: el de la crisis de credibilidad que padecen los institutos políticos 32 .

Otra opinión cualificada es la del político Rubén Zamora, para quien

Estamos, pues, en presencia de una contradicción de fondo que se constituye en la fuente de la crisis política actual: un sistema institucional de organización política y social que no corresponde a la etapa que la sociedad ha empezado a vivir... En otras palabras, las fuerzas políticas que han sido determinantes para empujar nuestra sociedad hacia la nueva etapa, se han quedado rezagadas, están atrasadas respecto al conjunto del país y de alli que se encuentren en crisis y no puedan cumplir con su papel...33.

Se puede estar o no de acuerdo con las racionalizaciones o con las intelecciones que cada quien hace sobre la crisis de los partidos políticos de oposición y en particular, acerca de la crisis del FMLN; sin embargo, es algo común a todos que existe una crisis, aunque cada quien destaque uno o varios elementos de la misma o insista más en el por qué de ella. En este sentido, la crisis se presenta como un hecho real, al representarse como una obviedad, como algo evidente. 
Al hablar de crisis "de" los partidos políticos afirmamos que estos institutos atraviesan una crisis política general, independiente de sus crisis internas, de lo cual se trataría de dar cuenta con el "en". La crisis general se manifiesta en la pérdida de credibilidad en los partidos políticos, así como en la política misma. La crisis "en" los partidos políticos se expresa en una serie de problemas internos como algunos de los ya citados, la "disputa" entre abrahamcistas y fidelistas en el caso del Partido Demócrata Cristiano, que de seguirse profundizando generaria una escisión, o lo que Gerson Martínez considera como "tendencias cismáticas [en el FMLN], tendencias inmaduras e irresponsables"34.

El hecho importante o fundamental seria la crisis de los partidos políticos de oposición en contraposición a los de la derecha, ya que ello limita la capacidad de incidir positivamente en la marcha de la historia, dejando un vacío político que debe ser llenado por las fuerzas sociales. En la medida en que nuestra perspectiva de análisis no es la sociedad civil, sino la sociedad popular, el hecho fundamental es la crisis de y en los partidos políticos de izquierda o progresistas, lo cual exige a las fuerzas sociales populares constituirse en una tercera fuerza, en el sentido de I. Ellacuría, a fin de velar por sus intereses particulares y por los de la sociedad popular en general.

No dudamos de que la crisis de los partidos políticos de izquierda será superada; sin embargo, ello no invalida la exigencia para que las fuerzas sociales populares se constituyan en una tercera fuerza. Cuando lo hagan, adquirirán suficiente peso político como para influir o determinar, en última instancia, el quehacer político de los partidos de izquierda o progresistas, como tambien se les suele llamar en un sentido más englobante.

\subsubsection{La preservación de las estructuras eco- nómicas y sociales injustas}

En los acuerdos de paz se relegó la temática económico social. De los pocos instrumentos surgidos de aquéllos, el único implementado fue el Foro de Concertación Económica y Social; sin embargo, éste resultó estéril no sólo por el sabotaje de los sectores empresarial y gubernamental, sino también por la falta de cohesión del sector popular, lo cual limitó en gran medida su capacidad para presionar y obtener algunos resultados positivos. De allí que si buscamos algún cambio estructural, considerando la firma de la paz como un punto de inflexión de nuestra realidad económica y social, nos encontramos más con hechos negativos que positivos. Entre estos último debemos mencionar la reforma agraria, al menos en su Fase I35, y alguna transferencia de tierra a los ex combatientes de uno y otro bando ${ }^{36}$. Pero eso no es todo, puesto que se ha retrocedido en la reprivatización del comercio exterior, de la banca y de las asociaciones de ahorro y préstamo, la cual se ha traducido en una centralización del capital mucho mayor que la existente antes de la nacionalización. Además, esta reprivatización se ha llevado a cabo de forma fraudulenta. Todo esto permite sostener sin mayores dificultades que las estructuras económicas generantes de pobreza y exclusión social siguen en pie.

Que ello es un hecho, parece indiscutible. La cuestión sería si se trata de un hecho fundamental, al punto de mantener de manera latente una de las causas - quizá la principal- del recién terminado conflicto bélico y al cual, seguramente, nadie desearía retornar. Sin embargo, este no sería un obstáculo para que se fuese incubando un estallido social con consecuencias impredecibles. En este sentido, el padre J. M. Tojeira advertia:

No habrá coherencia cristiana si no somos capaces de luchar contra las causas que generaron la guerra y que permanecen, algunas en menor medida, presentes en nuestra sociedad. Como tampoco la habrá si no nos preguntamos cada día cómo aliviar el dolor de tanta gente que en nuestro país sufre, no sólo por causas que no podemos controlar, sino también por una estructuración social que genera deshumanización y conflicto en muchos de nuestros hermanos ${ }^{37}$.

Para el Provincial de los jesuitas, el hecho al cual nos venimos refiriendo constituye un hecho fundamental en el área centroamericana. Fundamental en tanto fundante de una realidad tan cruenta que no sólo llamó la atención de la comunidad internacional, sino que exigió que ésta se ocupara 


\section{El hecho fundamental es la crisis de y en los partidos políticos de izquierda o progresistas, lo cual exige a las fuerzas sociales populares constituirse en una tercera fuerza.}

de la misma; sin embargo, existen tareas pendientes, como la transformación de las estructuras económicas y sociales injustas, que estaría exigiendo la conformación de la tercera fuerza, para transitar por el camino que nos aproxime a la verdadera solución, pero que a su vez sea una solución verdadera, la cual no se logró con la firma de los acuerdos de paz.

En este contexto cabe recordar las causas estructurales primarias del conflicto identificadas por el debate nacional, convocado por el arzobispado de San Salvador, en 1988, y aprobadas por más de la mitad de los participantes.

La raíz está en la injusticia estructural, manifestada en la concentración injusta de la riqueza, especialmente de la tierra, pero también de la industria y el comercio en grupos sociales pequeños, que marginan a la inmensa mayoría de los beneficios, imposibilitando la reproducción material y espiritual de la mayor parte de la población. La injusticia estructural está sostenida por la violencia institucionalizada y la represión, que mantiene al pueblo en condiciones inhumanas con negación de sus derechos fundamentales.

Subordinación del poder político al poder económico, de modo que el poder del Estado y de sus órganos se configura en beneficio de las minorías y para el mantenimiento del orden que les favorece, constituyéndose así en un sistema político excluyente, injusto, débil y represivo.

Un sistema educativo inadecuado para el desarrollo intelectual, moral y político de la mayor parte de la población 38 .

3.2.3. La pobreza y la marginación social agudizadas por la implementación del programa de ajuste estructural

La pobreza y la marginación social no son he- chos nuevos asi como su carácter de fundamentalidad tampoco lo es. Se trata precisamente de la consecuencia necesaria y obligada de la existencia de estructuras económicas y sociales injustas, pero esta realidad ha sido fortalecida por la implementación del programa de ajuste. Una interpretación ajena a la idolatría de los economistas neoliberales, más comprometidos con el salario que con la razón y la justicia, afirma lo siguiente:

No obstante el optimismo con que se han asumido y pregonado los éxitos del modelo de ajuste salvadoreño, persiste la preocupación sobre los magros resultados en materia social. Ahora en 1994, no sólo el nuevo gobierno, sino los organismos internacionales han reconocido la necesidad de ampliar y profundizar las acciones ya no solo de compensación social, sino de carácter más integral y sectorial tendientes a combatir la situación de pobreza.

Abandonando el triunfalismo desaforado, ahora se asumen conservadora y cautelosamente los éxitos y se los relativiza en función de los hechos que está mostrando la realidad social salvadoreña. Realidad social que - de suyoimpone el análisis reflexivo y crítico que aborde con seriedad y de manera estructural los problemas generantes de condiciones infrahumanas de vida de más del 50 por ciento de la población salvadoreña39.

Estas afirmaciones puden ser historizadas tomando en cuenta los datos sobre la pobreza de 1993, registrados por las Encuestas de hogares. En efecto, el 57.5 por ciento de la población era pobre, el 27 por ciento vivía en pobreza absoluta y el 30.5 en pobreza relativa 40 . Pero, en realidad, la situación es más grave aún, pues al elaborar estos estimados, en el ingreso de los hogares se incluyeron las remesas. La nueva canasta básica no se usó en estos cálculos, porque elevaría la línea de pobreza, pues considera un consumo normativo ma- 
yor. A pesar del incremento en la desocupación y cesantía, según los datos oficiales, el número de pobres habria disminuido. En consecuencia, las estadísticas oficiales no son confiables. Los datos oficiales deben considerarse como una fotgrafía borrosa de la realidad que es mucho peor de lo que se afirma.

Del total de la población económicamente activa ocupada, para 1993 el 47 por ciento se encontraba en el sector informal; los salarios mínimos reales han tenido en todos los años, a excepción de 1993, tasas de crecimiento negativo, siendo los más afectados los salarios del sector agrícola. Por su lado, una de cada diez personas en edad de trabajar no tiene empleo; el 50 por ciento de los niños menores de cinco años padece algún grado de desnutrición; la mortalidad infantil es de las más altas de América Latina; más del 27 por ciento de la población mayor de quince años es analfabeta; el 45 por ciento de la población no tiene acceso a agua, en el campo se incrementa al 63 por ciento y el 41 por ciento carece de servicios sanitarios.

En términos de la distribución del ingreso se refleja una situación de inequitatividad. Según el Ministerio de Planificación, el grupo de población urbana que experimentó el mayor crecimiento de ingreso real en 1992 fue el 10 por ciento con ingresos más altos y el grupo cuyo ingreso creció en menor proporción fue el comespondiente al 10 por ciento más pobre. Los mismos datos revelan que el 10 por ciento más pobre de la población urbana vio reducido su ingreso real en 1991, mientras el segundo decil refleja que el ingreso se estancó. Los datos permiten aventurar la hipótesis de que existe mayor concentración económica y persiste la caída del ingreso de los grupos más pobres, aumentando los niveles de pobreza en el país 41 .

Este hecho que, obviamente, es fundamental, tanto por su dimensión cualitativa como cuantitativa, a su vez se nos presenta como un hecho exigente de acciones conducentes a su verdadera solución que se constituya en una solución verdadera. Una alternativa podría ser la configuración de la tercera fuerza y quizá sea, si no la única, al menos, la mejor alternativa, dados los hechos refe- ridos con anterioridad.

\subsubsection{La carencia de alternativas globales: ni al modelo neoliberal, ni al sistema econó- mico-social}

Aunque este es un hecho de suyo bastante conocido, quizá amerite citar lo que manifiesta uno de los políticos más experimentados del país, quien sostiene que "nuestro principal problema y de toda la izquierda consiste en que tenemos un vacío estratégico, ¿hacia dónde nos estamos moviendo? ¿Por qué luchamos?42. Luego agrega, "el socialismo de Estado fracasó".

Por otra parte, si bien existen otras opciones políticas como la social democracia y la democracia cristiana, éstas no han logrado articular un modelo alternativo al neoliberal y en los países donde están o han estado en el gobierno, no han pasado de ser administradores del modelo neoliberal. Un sistema alternativo no es parte de su agenda, pues se sienten muy a gusto en el sistema capitalista, limitándose a soñar sueños imposibles para los países periféricos del tercer mundo.

Así, pues, por ahora, a diferencia del pasado, cuando el mismo FMLN proponía su Plataforma del Gobierno Democrático Revolucionario, la cual constituía efectivamente una alternativa real para el país, no se tiene ni siquiera algo equivalente. Ciertamente, este vacío es muy serio porque conduce a una serie de acciones sociales y políticas sin rumbo claro, sin horizonte definido. Por eso, en determinados momentos las actividades sociales y políticas no son convergentes, sino incluso opuestas. En consecuencia, este hecho exige la conformación de una tercera fuerza que siente las bases de lo que podría ser, en un primer momento, un modelo alternativo para transformarse después en un hecho posibilitante y exigir, andando el tiempo, un sistema alternativo.

\subsubsection{La debilidad del movimiento social ante la fragmentación y atomización de las fuerzas sociales populares}

Quizá el hecho que más revele la debilidad del movimiento social en la actualidad lo constituya el fracaso del Foro para la Concertación Económica 
y Social, pero lo mismo se puede decir de la falta de respuesta de los sectores sociales ante una serie de medidas y acciones del gobierno de ARENA, que afectan directa $o$ indirectamente a los sectores sociales populares, como los programas de privatización y de apertura comercial, la corrupción, la impunidad, la mera formalidad en el cumplimiento de algunos acuerdos, etc. Lo difícil no es seguir enumerando casos en los cuales se hubiese esperado o debería haberse dado una respuesta unificada, sino encontrar una acción o actividad en la cual las distintas fuerzas sociales populares hubiesen actuado de manera coordinada y monolítica. En consecuencia, la debilidad se manifiesta como un hecho obvio. La pregunta es, entonces, ¿están fragmentadas y atomizadas las fuerzas sociales populares?

Tanto el movimiento sindical como el sector campesino sin tierra, el sector cooperativo, el informal, el público, el marginal, el de mujeres, etc., se encuentran atomizados y fragmentados. Aquí nos detendremos en el movimiento sindical porque es el que posee mayor tradición organizativa. En otros sectores, el problema mayor ha sido y aún sigue siendo, aunque en menor medida, la falta de organización. Esta atomiza su actividad e impide la existencia de un movimiento social.

De acuerdo con la información de Arriola y Candray, el movimiento sindical obrero está integrado por las siguientes organizaciones: UNTS con tres federaciones (FUSS, FESTIAVTSCES y FEASIES) y un total de 44 asociaciones y sindicatos; UNOC con tres federaciones (CTD, OSILS Y CTS) y veinte sindicatos y asociaciones; FENASTRAS con dieciocho sindicatos; CGS con tres federaciones y catorce sindicatos; FESINCONSTRANS con nueve sindicatos y CGT con siete sindicatos y asociaciones.

En el Foro para la Concertación Económica y Social participaron ocho organizaciones del sector laboral (UNTS, UNOC, ADC, CGT, CTS, FESINCONSTRANS, AGEPYM y UPD). Las bases de la Alianza Democrática Campesina (ADC) están integradas por organizaciones de trabajadores agrícolas y por cooperativistas agropecuarios. La CTS no tiene sindicatos en el sector privado y al igual que AGEPYM y UPD, entes gremiales, no

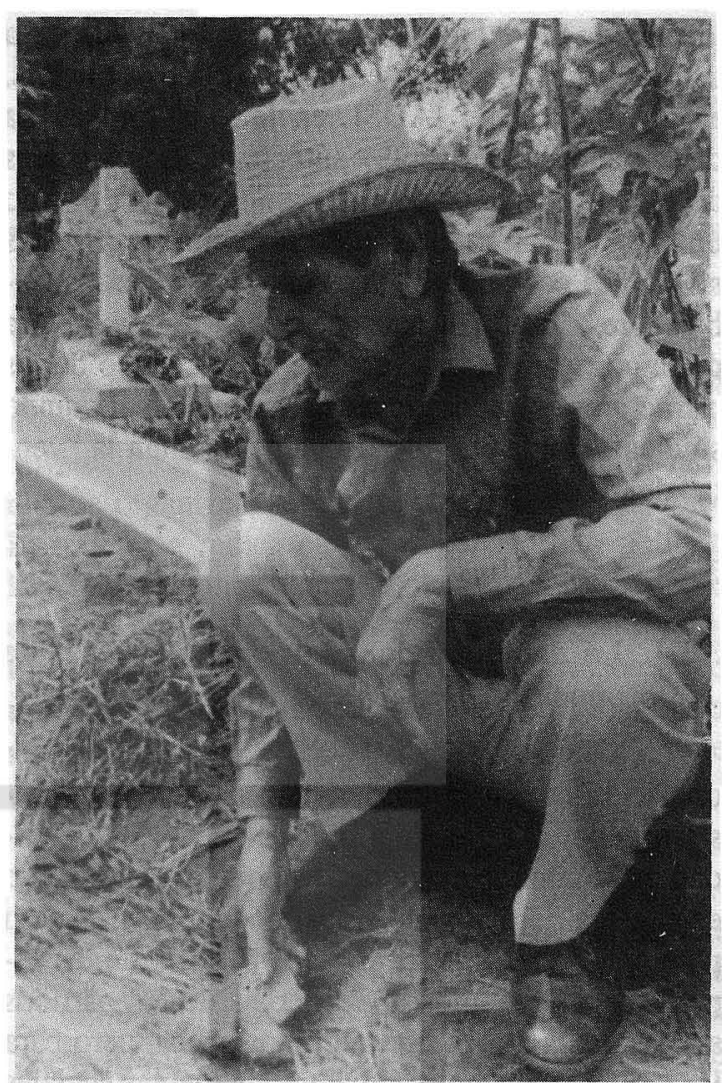

tiene base sindical 43 .

El movimiento sindical se caracteriza, según los autores citados, por un escaso nivel de afiliación, por una elevada fragmentación organizativa y por la dispersión sindical. Las causas de esta situación serian, en primer lugar, la cultura antisindical del empresariado salvadoreño y la legislación intervencionista de un Estado subordinado a las fracciones dominantes del capital, que busca controlar a los trabajadores y no normativizar unas relaciones laborales basadas en la negociación colectiva44. Este comportamiento empresarial y legal está determinado por las características del modelo de acumulación, basado en la sobre-exploración de la fuerza de trabajo.

La segunda razón obedece a la coyuntura de la guerra. El movimiento sindical es la institución que mayor coste ha pagado en la década de la guerra civil. Sus estructuras, poco adaptables al trabajo clandestino, fueron sistemáticamente atacadas por la contrainsurgencia y el capital. Otra causa es 
la falta de autonomía del movimiento sindical. La excesiva ingerencia externa de partidos políticos, empresarios y del IADSL en la vida sindical ha dificultado su desarrollo autónomo. Los avances de los últimos años en este campo no han podido eliminar la determinación de los comportamientos sindicales por parte los agentes externos a los trabajadores. También hay que considerar la cultura de la corrupción, un componente endémico de las estructuras estatales que se ha trasladado al mundo sindical, donde los salarios bajos facilitan la "venta" de los dirigentes.

\subsection{Los hechos posibilitantes}

\subsubsection{La debilidad de los partidos políticos de oposición}

La debilidad de los partidos políticos de la oposición es un hecho derivado de su propia crisis, es como la otra cara de la moneda. La debilidad es la consecuencia de la crisis. Lo importante es que esa debilidad está posibilitando dar el paso para conformar la tercera fuerza. De hecho, es esperamos y deseamos que la crisis de los partidos sea superada, tal como lo dijimos arriba, pero para lograr una nueva relación entre las fuerzas sociales y políticas, es preciso que ambas sean realmente fuerzas. Por eso, algunos hablan de modemizar la vida política; pero Zamora advierte que

es necesario ir más allá de una modernización, se trata de refundar la política, de encontrar y desarrollar, a partir de una crítica seria a nuestro pasado inmediato, un nuevo lenguaje político, una nueva práctica política, una nueva forma de relación entre la sociedad política y la sociedad civil...45.

Esta nueva forma de relación es clave, pero el papel protagónico no se le puede dejar únicamente a los políticos. Las fuerzas sociales tampoco lo tendrán sin superar la atomización actual. Por eso, la debilidad actual posibilita avanzar hacia la conformación de la tercera fuerza.

\subsection{La apertura de espacios políticos antes y después de los acuerdos de paz}

En 1988, la mayoria de los participantes en el debate nacional sostenía:

se han abierto ciertos espacios políticos en nuestra vida nacional, tales como apertura de medios de comunicación social, ejercicio de ciertas libertades públicas, legalización de nuevos partidos políticos. Asi como una mejoría relativa de algunos derechos fundamentales de la persona. Todo ello debido fundamentalmente a la presión de los distintos sectores sociales del país ${ }^{46}$.

En la actualidad habría que añadir la existencia de varias emisoras nuevas (YSUCA, Doble FF, Maya Visión, Venceremos) con cobertura nacional así como otras emisoras comunitatias que, excepción de Venceremos, no tienen carácter comercial. También hay que agregar la publicación de nuevas revistas y semanarios pluralistas y con tendencia progresista.

Al haber desaparecido los cuerpos represivos, al desplegarse la Policia Nacional Civil, al introducirse algunos cambios en la Fuerza Armada, al legalizarle el FMLN, al establecerse la Procuraduría para la Defensa de los Derechos Humanos, etc., se ha producido una mayor apertura para ejercer las libertades públicas.

Ciertamente, si algo produjeron los acuerdos de paz fueron cambios a nivel supraestructural. Cuando I. Ellacuría formuló la tercera fuerza le vio alguna posibilidad, pero ahora existen hechos reales que claramente posibilitan su conformación. Existe un entorno mucho más favorable que en los años de la guerra para avanzar en el camino de su constitución. $O$ en otras palabras, existen factores externos a las fuerzas sociales populares mismas que, lejos de obstaculizar su conformación, la favorecen. Sin embargo, en su interior pueden existir algunos hechos reales que no animan a sus integrantes a dar este paso. De ello, no nos ocuparemos, ya que preferimos que sean ellos mismos los que manifiesten su disposición para conformar una tercera fuerza o lo ventajoso que sería ser parte de una poderosa fuerza social popular. Nuestro trabajo se reduce a señalar la exigencia y la posibilidad de conformar la tercera fuerza. Si el problema se redujera a cosa de nombres, se trataria de la conformación de una poderosa fuerza social popular. en los términos explicados, pero nada más. 


\section{Por eso, la debilidad actual posibilita avanza hacia la conformación}

de la tercera fuerza.

\subsubsection{Las formas organizativas nuevas desarro- lladas de los últimos años}

En la década pasada y en la actual ha surgido un cúmulo de nuevas organizaciones de la sociedad civil y, particularmente, de la sociedad popular, entre ellas están asociaciones campesinas como la Asociación Democrática Campesina, y las cooperativas del sector reformado, las cuales se han aglutinado en federaciones e incluso en confederaciones. Además de las cooperativas están las comunidades de repatriados y repobladores, las cuales tienen no sólo su organización comunitaria, sino que a su vez conforman organizaciones gremiales zonales y en algunos casos hasta a nivel nacional47.

Igualmente existe un cúmulo de organizaciones en el denominado sector informal urbano, algunas de reciente conformación como CONAMIS. También se está reactivando la organización en las comunidades marginales urbanas, donde el Movimiento Comunal Salvadoreño, por ejemplo, tiene bastante trabajo. Están también las organizaciones de mujeres, Las Mujeres por la Dignidad y la Vida, Centro de Estudios de la Mujer "Norma Virginia Guirola", Movimiento de Mujeres "Mélida Anaya Montes", la Asociación de Mujeres Salvadoreñas, Centro de Estudios Feministas, Red por la Unidad y el Desarrollo de las Mujeres Salvadoreñas, Instituto de Investigación, Capacitación y Desarrollo de la Mujer, etc. También es importante la existencia de más de 200 organizaciones no gubernamentales.

A partir de todas estas organizaciones y asociaciones, la existencia de nuevas formas organizativas es un hecho real. Pese a cierto grado de fragmentación, lo importante es la existencia de estas nuevas formas de organización de la sociedad popular. Desde esta realidad existente se podría avanzar hacia una organización mayor, es decir, hacia la tercera fuerza.

\subsubsection{La tendencia generalizada de la sociedad civil a una mayor presencia en el queha- cer nacional}

La tendencia de la sociedad civil a tener una mayor presencia en el quehacer nacional es una obviedad. La simple existencia de una gran cantidad de organizaciones es la mejor prueba de ello. El problema radica en que algún partido político ha tenido alguna ingerencia en el establecimiento o en el desarrollo de muchas de estas organizaciones; en la década pasada, en algunos casos hubo una instrumentalización clara. Sin embargo, esto está cambiando de forma acelerada, al punto que el director de un semanario decía que

Impera en nuestra sociedad una mentalidad generalizada de que detrás de toda iniciativa ciudadana o de la sociedad civil deben existir ocultos intereses de un partido político... Se trata de una perversión paternalista que concibe a la ciudadanía y a la sociedad civil como entes paralíticos que sólo pueden moverse bajo la influencia de los partidos 48 .

Pero eso no es todo. Con el surgimiento de nuevos medios de comunicación social y con la apertura en otros, la ciudadanía se manifiesta, ya sea de manera individual o representando alguna organización social. Durante la década pasada, la represión institucionalizada impedía tales manifestaciones, pues las tribunas para hablar públicamente eran muy pocas. Precisamente por ello, el padre Ellacuría estableció la Cátedra de Realidad Nacional en la universidad. Esta cátedra buscaba abrir ese espacio para la participación ciudadana. Tuvo una acogida excelente, tanto que en la actualidad abundan los foros, seminarios, talleres, mesas redondas, etc.

La participación de la sociedad civil va desde las denuncias de corrupción hasta la falta de agua potable en una colonia desconocida. Todo ello se presenta como un hecho real y evidente. Sin em- 
bargo, se trata todavía de esfuerzos aislados que, precisamente por ello, no consinguen el efecto deseado. Ahora bien, en la medida en que no existe apatía, esas acciones posibilitan el avance hacia la conformación de la tercera fuerza. De hecho, ya existen algunos esfuerzos en esta dirección como la conformación del Centro Cívico Democrático, la Iniciativa Ciudadana y quizá también la Iniciativa Social para la Democracia.

Bien mirado el fenómeno, se comprueba la existencia de una tendencia hacia una mayor participación de la sociedad civil en el quehacer nacional. Esta participación permite la organización, ya que la apatía no está referida al hacer político, sino al hacer político tradicional, dada la pérdida de credibilidad que pesa sobre los partidos políticos de la oposición.

\section{Conclusiones}

La propuesta de Ellacuria para conformar una tercera fuerza o una fuerza social popular que sea la antítesis de la Asociación Nacional de la Empresa Privada tiene validez en la actualidad. En este sentido, debe destacarse y reconocerse el aporte visionario y profético del rector mártir de la UCA. La claridad de su pensamiento continúa iluminando los senderos por los cuales deben transitar las mayorías populares.

Creemos haber mostrado que los hechos que exigen y posibilitan la conformación de la tercera fuerza son reales, en consecuencia, desde una perspectiva realista, la constitución de la tercera fuerza no sólo es necesaria, sino también posible. Por eso conviene recordar esos hechos así como preguntarnos si los aceptamos como tales. Hechos como los siguientes exigen la tercera fuerza: la crisis de y en los partidos políticos, sobre todo los de la oposición y en particular el FMLN; la preservación de las estructuras económicas y sociales injustas; la pobreza y la marginación social, agudizada por la implementación del programa de ajuste estructural; la falta de alternativas globales al modelo neoliberal y al sistema económico social; la debilidad del movimiento social ante la fragmentación y atomización de las fuerzas sociales populares.
Los hechos posibilitantes son los siguientes: la debilidad de los partidos políticos de la oposición, la apertura de espacios políticos antes y después de los acuerdos de paz, las nuevas formas organizativas de los últimos años y la tendencia generalizada de la sociedad civil a tener una presencia mayor en el quehacer nacional.

Para que la tercera fuerza se constituya en la realidad vislumbrada por Ellacuría, deberían evitarse los errores del pasado, cuando ésta buscó objetivarse por medio del Comité Permanente del Debate Nacional. Los errores que debieran evitarse son el alineamiento con partido político determinado, el hegemonismo, la no representatividad popular, el sectarismo y el dogmatismo. Ni principismo ni pragmatismo, clamaba Ellacuría, debemos ser realistas. Esto debe ser considerado seriamente si deseamos que la sociedad popular se convierta en sujeto con capacidad para empujar la historia por el rumbo de los intereses populares.

Ciertamente, la tarea propuesta no es sencilla, pero eso no exime de la responsabilidad de intentar llevarla a cabo y quizás hechos como la privatización debieran bastar para animamos a hacer nuestro mejor esfuerzo para implementarla. Cuando la lucha se hace aisladamente, sin una visión de la totalidad, no sólo no se articulan buenas propuestas alternativas, sino que no se es eficaz por no tener la fuerza suficiente.

A algunos podrían preocuparle las relaciones de la tercera fuerza con los partidos políticos o el que aquélla pretenda reemplazar a éstos. Aunque ambas inquietudes son válidas, son infundadas, pues tal como señaló Ellacuría, la propuesta consiste en que el pueblo recupere su protagonismo activo sin someter su fuerza y su posible organización, y mirando por sí mismo y por sus intereses, sin delegarlos, al menos en un primer momento, en ninguno de los poderes que se disputan el mando del Estado. Por lo tanto, existen dos momentos. En el primero, el pueblo recuperaría su protagonismo activo al constituirse en una fuerza social popular con fuerza política, pero sin ser política, ya que su meta no es acceder al poder dél Estado. En el segundo momento, una vez constituida la fuerza política, la tercera fuerza recuperaría su 
protagonismo por medio de sus acciones organizadas. Entonces podrá incidir en la actividad de los partidos políticos, en el quehacer del gobierno y en conyuntura trascendentales buscaría la forma más conveniente de relación con los partidos políticos, desde integrar un bloque de opinión hasta delegar la representación de sus intereses en un partido determinado, pasando por diverso tipo de alianzas. La problemática concreta determinará la relación más conveniente y realista con los partidos políticos.

\section{Notas}

1. Cuando hablamos de un partido de inspiración marxista, no lo estamos haciendo a partir de la visión estereotipada que se tiene del marxismo, mucho menos desde la concepción dogmárica que fue propia de los partidos comunistas tradicionales. Tampoco lo concebimos de manera ortodoxa. Para nosotros, lo fundamental del pensamiento de Marx se encuentra en sus obras económicas, las cuales nos permiten comprender la esencia del modo de producción capitalista, esencia que no ha cambiado y por ello, precisamente, es que sigue teniendo vigencia la teoría de Marx. Pero no obstante lo anterior, la realidad, nuestra realidad concreta y particular, no se reduce a las formulaciones de Marx. De allí que un seguidor del pensamiento de Marx. no debe de limitarse a repetir sus planteamientos, sino que a desarrollarlos y a estudiar lo que Marx no estudió, etc. Y con todo ello, debe articular un pensamiento adecuado a nuestra realidad ya sea en lo económico, como en lo político, en lo social, en lo ideológico, etc. En consecuencia, un partido de inspiración marxista será aquel que, a diferencia de otras corrientes ideológico-políticas, ya sean reformistas como la democracia cristiana y la social democracia, o conservadoras como los partidos liberales, republicanos, etc., tenga como finalidad última la construcción de una nueva organización social que se constituya en la negación dialéctica de la sociedad capitalista, sin por ello renunciar, en el corto y mediano plazo, a participar en la lucha de los sectores explotados, expoliados y marginados, por conquistar mejores condiciones de vida y de trabajo.

2. Eso es propio de los partidos electoreros, oficiales o de oposición, pero un partido de y para los sectores populares que, día tras día, está vinculado y luchando a la par de ellos no necesita, ni tiene recursos para pretender convencer o persuadir a estratos de la población que no le darán nunca sú voto, poî más dinero que derroche en los medios de comunicación masiva, ante la proximidad de un evento electoral, por lo cual, tampoco debería derrochar sus recursos, aun en el caso de poseerlos.

3. Schafik Handal le denomina "socialismo de Estado" y le contrapone el "socialismo socializado".

4. Antonio González, "Orden mundial y liberación", ECA, 1994, 549, p. 630.

5. I. Ellacuría, “Utopia y profetismo", Mysterium liberationis, San Salvador, 1990.

6. Adicionalmente, cuando la izquierda habla de justicia social, de que es necesario crear condiciones de vida dignas para los trabajadores, obviamente, de lo que se trata es de que los trabajadores tengan acceso a aquellos bienes que ellos producen, pero que no pueden disfrutar. Por ejemplo, no hay mayor ironía que la de los obreros de la construcción. quienes pasan su vida construyendo casas y al final, no tienen ni siquiera donde caer muertos.

Por otra parte, la propiedad personal ya sea un medio de trabajo -un pequeño comercio, un taller, un vehículo de transporte, una parcela de tierra, etc. $\longrightarrow$ un medio de vida -la casa, los muebles, los electrodomésticos, el carro, etc.- no sólo son derechos legítimos de los trabajadores, sino que a nadie que se considere de izquierda, inclusive si es marxista y es sensato, se le ocurriría estar en contra de la propiedad personal, ya que lo que se busca es que tales bienes no sean exclusivos de una minoría que se hace cada vez más rica, gracias a la propiedad privada capitalista, y que para conservar sus privilegios busca preservar el poder político, impidiendo con ello que se avance, aunque sea de manera paulatina, hacia la justicia social.

7. A. M., "Diez tesis acerca de la "nueva realidad", ECA, 1994, 547-548.

8. I. Ellacuría, Veinte años de historia de El Salvador, (1969-1989), Escritos políticos, Tomo II, San Salvador, 1991, p. 1162. La interrogante entre paréntesis es nuestra.

9. Ibid., p. 1127. Estos planteamientos fueron formulados en noviembre de 1985.

10. Aunque Eduardo Sancho manifiesta que "Los acuerdos de Chapultepec constituyen el único consenso mayoritario [sic] del siglo XX en El Salvador. No ha existido un acuerdo tan consensuado $y$ apoyado por todos los sectores de la sociedad. En él participaron todos los sujetos políticos del país: la Fuerza Armada, los partidos políticos, el FMLN, los profesionales, los artistas, etc.". Diario Latino, 1 de noviembre de 1994. Sin embargo y muy a pesar del ex comandante, sus afirmaciones nos confirman que las mayorías populares no participaron en el acuerdo.

11. Op. cit., p. 1128. 
12. Ibid., p. 1130.

13. Ibid., pp. 1130-1131.

14. Ver I. Ellacuría "Utopía y profetismo", en Mysterium Liberationis, San Salvador, 1990.

15. Op. cit., pp. 1132-1133.

16. Ibid., pp. 1128-1129.

17. Ibid., pp. 1163-1164.

18. La deuda agraria, los intentos para parcelar las cooperativas, la carencia de créditos y de asistencia técnica, la falta de canales para la comercialización. etc.

19. Inseguridad en cuanto a la tierra, carencia de servicios eléctricos, agua potable, etc., el abandono del gobiemo en cuanto a la salud y a la educación, y la falta de comprensión en cuanto a la estrategia anti-pobreza que estas comunidades están intentando implementar.

20. La falta de una política económica sectorial que capte el carácter heterogéneo del sector $\mathrm{y}$, en consecuencia busque apoyar a quienes más lo necesitan. La ausencia de un sistema de previsión social, etc.

21. Para éstos los problemas fundamentales, adernás de la carencia de empleo o los bajos ingresos, son la ausencia de vivienda digna, salud, educación, salubridad y servicios básicos, y el predominio de la delincuencia, la promiscuidad, etc.

22.. A los ya seculares de falta de apoyo técnico y crediticio, se añaden el incremento de los precios de los insumos y la liberación de las importaciones, lo cual podría conducir a su desaparición, generando un serio problema en términos de seguridad alimentaria, las bajas remuneraciones y la ausencia de empleo permanente.

23. Para los empleados públicos y privados sigue siendo un serio problema el salario bajo, que sencillamente no basta para satisfacer los componentes de la canasta básica ampliada. Además, para los trabajadores del sector público pende como una amenaza el despido ante la contracción del aparato estatal y la privatización.

24. A este sector, el libre comercio lo condena a su desaparición, si no el gobierno no toma medidas para garantizarles seguir operando en condiciones de total desventaja y desigualdad.

25.. La falta de cumplimiento de importantes acuerdos que posibiliten su inserción económica, además de otros problemas de índole psicológica o de discapacitación.

26. Ibid., p. 1133.

27. Ibid., p. 1165 .

28. Ibid., p. 954.

29. "Una verdadera solución es aquella que realmente resuelve el problema... Una solución verdadera es, a su vez, aquella que no sólo resuelve, de hecho, un problema, sino que lo resuelve definitivamente, porque realmente se acomoda a las raíces del problema y propone realistamente los remedios profundos adecuados, que son a la vez adecuados y justos" (Ibid., p. 954).

30. Ibid., p. 955.

31. Las tres opiniones siguientes fueron obtenidas en entrevistas con las personas citadas.

32. Diario Latino, 10 de octubre de 1994.

33. Diario Latino, 5 de octubre de 1994.

34. Diario Latino, 21 de noviembre de 1994.

35. En 1988, se estimaba que en las cooperativas había 30,268 productores, lo cual representaba apenas el 8.7 por ciento del total de productores. Ver A. Montoya, El agro salvadoreño, antes y después de la reforma agraria, Cuademo de Investigación № 9, CENITEC, 1991.

36. Según el Primer Censo Agropecuario del Programa de Transferencia de Tierras de agosto de 1994 "a la fecha de realización del estudio se ha logrado legalizar la transferencia de 30,158.5 has., para un total de 11,041 personas; asimismo se consideran en calidad de tierra asignada $12,442.4$ has., para 3,326 tenenedores y excombatientes del FMLN".

37. J. M. Tojeira, homilía con motivo del quinto aniversario del martirio de los padres jesuitas y dos empleadas. En esta edición de la revista.

38. Ver $E C A, 1988,478-479$.

39. Sonia I. Sánchez, "Las reformas estructurales y lucha contra la pobreza". Ponencia en el seminario organizado por el CIEDLA, San José, octubre de 1994.

40. Proceso, 635, 9 de noviembre de 1994.

41. Ibid.

42. Intervención de Schafik Handal en la discusión sobre estrategia, octubre de 1994.

43. J. Arriola P. y J. A. Candray, Derechos prohibidos. Negaciación colectiva y sindicatos en El Salvador. Serie Documentos de Investigación. UCA, mayo de 1994, pp. 38-39.

44. En toda la historia del país, tan solo tres huelgas han sido declaradas legales.

45. Diario Latino, 5 de octubre de 1994.

46. Op. cit.

47. Entre las organizaciones de comunidades tenemos el CCR en Chalatenango, PROGRESO en Cuscatlán y Cabañas, UCRES en el norte de San Salvador y La Libertad, CODESMA en el sur de La Libertad y el CDR en el sur de San Vicente. Todos estos organismos forman parte de CRIPDES. Otro ejemplo sería PADECOES, integrado por Comunidades Unidas de Usulután, Comité de Solidaridad para el De- 
sarrollo de las Comunidades de San Miguel, Coordinacion para el Desarrollo Comunal de La Unión, Patronato para el Desarrollo de las Comunidades de
Morazan y San Miguel.

48. H. Castellanos Moya "La aberración de lo partidario", Primera Plana, No. 10. 